\title{
Phenomenon of Education: Philosophical and Methodological Aspects of Research
}

\section{Феномен образования: Философско-методологические аспекты исследования}

\author{
Received: March 8, 2021 \\ Accepted: April 15, 2021
}

\author{
Written by: \\ Yuri V. Kryanev ${ }^{36}$ \\ https://orcid.org/0000-0002-1200-8515 \\ https://www.elibrary.ru/author_profile.asp?id=844227 \\ Tatyana P. Pavlova ${ }^{37}$ \\ https://orcid.org/0000-0002-2674-496X \\ https://www.elibrary.ru/author_profile.asp?id=821104 \\ Daniil A. Kvon ${ }^{38}$ \\ https://orcid.org/0000-0003-2030-9550 \\ https://www.scopus.com/authid/detail.uri?authorId=57211552416
}

\begin{abstract}
The purpose of the work is to identify in the study of education, as a socio-cultural phenomenon, its functional and structural-organizational features at different historical stages of development and to analyze the relation of the concepts of "education", "science" and "intelligence". Methodology and research methods used in the study are the following: comparative analysis method, systematic approach, functional and cultural approaches and philosophical reflection. Key findings are the following: strategy of introducing new standards in the educational process in connection with the transition to digital reality requires changing the educational methodology and creating a new format for the development of teaching methods. The relation between the concepts of "methodology", "education" and "science" are ambiguous, their use is contextual. The main method of analysis of the study of functionality is philosophical reflection, which reveals their meaning and purpose. As a result of the study of the functional, structural and organizational features of education, the necessary object (material or spiritual) of research is created, where the relation between science and education is revealed. The question of the relation of research methodology and methods of the educational process becomes a question of the interactions of spirituality and science, values and knowledge.
\end{abstract}

\section{Резюме}

Целю исследования является выявить при исследовании образования, как социальнокультурного феномена, его функциональные и структурно-организационные особенности на разных исторических этапах развития, проанализировать отношения понятий «образования», «наука», «интеллект». Используемая методология и методы исследования. Метод сравнительного анализа, системный подход, функциональный и культурологический подходы, философская рефлексия. Основные выводы: Стратегия введения новых стандартов в образовательный процесс в связи с переходом в цифровую реальность требует изменить методологию образования и создать новый формат для разработки методик обучения. Взаимоотношение понятий «методология», «образование», «наука» многозначны, их использование носит контекстуальный характер. Основным методом анализа изучения функциональности является философская рефлексия, которая выявляет их смысл и предназначенность. В результате исследования функциональных и структурноорганизационных особеностей образования создается необходимый объект (материальный или духовный) исследования, где выявляются взаимоотношения науки и образования. Вопрос о взаимосвязи методологии исследования, методик образовательного процесса

\footnotetext{
${ }^{36}$ Doctor in Philosophical Sciences, Professor, Moscow Aviation Institute (National Research University), Moscow, Russia.

${ }^{37} \mathrm{PhD}$ in Philosophical Sciences, Associate Professor, Moscow Aviation Institute (National Research University), Moscow, Russia.

${ }^{38} \mathrm{PhD}$ in Political Sciences, Associate Professor, Moscow Aviation Institute (National Research University), Moscow, Russia.
} 
Keywords: education functionality, educational concepts, educational process, intelligence, research methodology.

\section{Introduction}

The philosophical and methodological aspect of the analysis of the basic functions of education is associated not only with the need to create a new education paradigm, but with a change in thinking, angle of view on the processes and prospects of the modern educational process. They are becoming aware of the problem of education as a strategic resource not only for the country's social or economic development, but also as a condition for a future dynamically developing future. Understanding these circumstances requires the development of an adequate methodology that allows not only to identify the main functions of modern education, but also an understanding of the educational process as the main factor in the country's spiritual identity.

Education is a process of formation and development of a person's abilities to live in peace with himself and with other people, to ensure his existence and the continuation of the life of the human race. It enriches the inner world of a person, introduces him to the world cultural heritage, makes it possible to correctly assess political, economic and moral environment of the world around him.

The activation of its subjective components (teacher and student) has a certain significance in the structure of education, taking into account their individuality and creativity. "The purpose of such education is a personality, and then professional necessary subjects in the educational process are evaluated not as a dogmatically learned alien (or anonymously universal) experience, but as characteristic features of one's own subjectivity" (Belkin, 2000).

The development of theoretical knowledge allows their application in various fields of human activity. Modernization of the educational environment is impossible without the introduction of the latest information technologies. The emergence of new technology requires the formation of a new worldview based становится вопросом о взаимодействиях духовности и научности, ценностей и знания.

Ключевые слова: интеллект, методология исследования, образовательные концепции, образовательный процесс, функциональность образования.

on the ability to use the methodology of scientific research.

Education through its structures creates reference centers of knowledge that implement three main functions: professional, social, and cultural. A systematic approach to the study of the formation of education in different historical eras shows that education has always been the bearer and condition for understanding the new thing. In this regard, it is always innovative.

The aim of the article is to single out the main characteristics of the phenomenon of education, determine the functions of educational paradigms and analyze the methodology for the formation of a scientific worldview in the research activities of educational institutions.

\section{Theoretical Basis}

Analyzing the tasks and functions of education in its historical development, we need to take into account the experience of Ancient Greece, first of all, legacy of Socrates, Plato and Aristotle. Subsequently, all European thinkers relied on the ideas of these philosophers or argued with them, developing their concepts of education. In Greece the most important structural elements of education, such as school, lyceum and academy, were laid. The main task of classical education was to transform the state with the help of a public education system. In Greece, it was interpreted as an education for free people called to rule the state. Practical knowledge, according to philosophers of ancient Greece, was the lot of artisans. This educational system was characterized by the following features: contemplation, lack of understanding of the cognitive significance of experience, but on the other hand, the prerequisites were created for the formation of science, primarily, the transition from mythological thinking to logical-conceptual (rational).

With the development of European civilization, there is a long transformation of knowledge: classical ideal of a unified scientific and 
philosophical knowledge gradually breaks up, generates disciplinary fields separate from philosophy, which at the same time leads to an ever-greater differentiation of educational practices and systems. Western Europe of the XVII-XVIII centuries entered the phase of a new industrial revolution, formation of new classes and layers of society. It required new methodologies in the educational process.

In the New Age period, the formation of the classical paradigm of education takes place in the general context of the development of science, philosophy, and art. Philosophical technologies for the modernization of university education are reflected in two concepts: ideas of a research university (Germany) and of an intellectual university (England).

W. Humboldt (1767-1835), philosopher, humanist, encyclopedically educated scientist, in contrast to the medieval concept of the university, based his model on the idea of the university as a place for free scientific work (Humboldt, 1985). He was the first who tried to develop the idea of university education, where new relations between the study of theoretical and empirical knowledge should have been laid. He believed that science exists in the form of research processes, and the level of welfare of the state is determined by the results that science brings. W. Humboldt has strongly opposed the differentiation of science and higher education. The goal was founded in 1810 by the University of Berlin, which became a new type of university (Humboldt, 1985). This made it possible for the natural sciences to free themselves from a religious worldview and become a source of development of applied knowledge aimed only at the practical result of research.

A supporter of other philosophical technologies in the XIX century, the educational process of the university was the Englishman John Newman (1801-1890). He believed that the goal of University is education, not a simple transfer of knowledge (Newman, 1996). The mission of University is to protect and transcend the spiritual wealth of the society. In "Discussion of the Purposes and Nature of University Education", which later became world-famous as "Idea of University" (1873), J. Newman outlined his concept of education renewal (Newman, 1996). There was a fierce struggle for the modernization of higher education unfolded in England in the first half of the XIX century, when new personnel was required during the industrial revolution. A sharp debate on the issue of education took place between the adherents of the concept of utilitarianism and the proponents of classical education.

D. Newman opposed the ideas of the founder of the utilitarian understanding of education, John Locke (1632-1704), who insisted on including only disciplines in university programs that would correspond to the "principle of utility", that is, provide specific knowledge useful for practical application (Locke, 2001). J. Locke justified the philosophy of common sense and came to the perception of ideas and concepts in an experimental way, comparing the mind of the learner with the "pure board" (tabula rasa). He believed that it was important to understand the possible limits of the degree of knowledge, as this would "make the active spirit of man to be more careful and not to engage in things beyond his cognitive power, to stop at his extreme limits of knowledge" (Locke, 2001).

D. Newman believed that the purpose of the university is education, and not a simple transfer of knowledge. The mission of the university is to protect and transmit the spiritual wealth of society. The university should train intellectual gentlemen. He believed that philosophical training provides starting points for the correct orientation of mental activity (Newman, 1996).

However, unlike Humboldt, practical research and training, from his point of view, represent various functions. These functions should be divided between a scientific academy and university education. Subsequently, homo sapiens (intelligent man) and homo faber (practical man) will form the antithesis of education throughout European history.

In the formation of the Russian mentality, religion played a larger role than in Europe. The spiritual space of Russian culture in the New Age was not ready to accept and assimilate the European traditions of professional natural science research on nature. For the religious life of our compatriots of the XVI-XVII centuries, ritualism was characteristic of the desire to reduce religion to the careful observance of rituals. Our spiritual fathers of that period in matters of faith strayed from "opinions" as later Slavophiles strayed from "rationalism". As P.N. Milyukov notes, that Orthodox teachings were justified and furnished with evidence only when they had to be contrasted with nonOrthodox to refute the latter. In the XVI century for this purpose it was considered sufficient to compare the provisions of the Holy Scriptures and the Church Fathers. The church must be infallible, and "to prove dogma for the members 
recognizing its divine authority is superfluous work" (Milyukov, 2013). There was no antipode "Knowledge - Faith" in Russia as there was in the West, but there was "Knowledge and Faith" on the one side, and "Ignorance" on the other side. The Orthodox tradition of transmitting spirituality is not authoritarian. Here, a person perceives the truth as a "side" vision, using examples, reading the lives of saints, listening to church sermons and chants. In Russia, philosophy has been studied in Greek-Latin schools since the XVIII century, but it was completely subordinate to the Holy Scriptures.

At the beginning of the XIX century, following the reform of the secular education system, a plan was made for a radical transformation of the spiritual school. Hegel described very expressively the process of philosophical awakening, it is a painful historical process, but it necessarily sets in, and every nation has a certain philosophy with its own particular questions. Such a philosophical awakening occurred in Russia only at the turn of the 18201830 s. In 1830, I. Kireyevsky openly declared that we needed a philosophy, that the "whole development of our mind requires it" (Kireevsky, 2014). German philosophy had a great influence on the awakening of thought in Russia.

Philosophical circles began to appear in Moscow and Saint Petersburg, and philosophical magazines appeared. University professors of philosophy also came out of the theological academies for a long time. The teaching of philosophy at Theological Academies was quite extensive, but selective, since only German idealism was allowed to be studied, and English and French philosophers were not favored. Revolutionary protests in the West and peasant movements in Russia provided a new impetus to reactionary actions from the government.

Only in religious school's philosophy, as a subject of teaching, eludes the prohibitions of the period of Nikolas I (Tsvyk, 2011). The Theological Academies of Moscow, Kiev, and Saint Petersburg create a special atmosphere of philosophical observation. The problem "Philosophy - Theology" was posed rather sharply and frankly, but it was solved in different ways. Thus, theological schools of Russia laid the foundations for a systematic philosophical culture. It becomes clear why at the end of the XIX century the Theological Academies of Russia experienced the peak of church science (Tsvyk, 2011). Byzantine-Russian Orthodoxy, based on a non-rational philosophy of revelation, considered possible to widely use rationalintellectual tools in auxiliary theological areas. On the other hand, in the culture of Russia in this period there were no prerequisites, as in Europe, which would allow science to acquire independence. Scientific knowledge is always theoretical and rational. It is characterized by objectivity, logic, specific language. The main category of science is "knowledge" and not "faith" or "opinion".

So, the classical paradigm of education comes from the position: "science - education practice". Science through experience reveals the eternal and unchanging laws, which are knowledge, and education translates them. Other ways of knowing and mastering the world remained outside the scope of this logical scheme.

The formation of a non-classical philosophy of education is characterized by a predominant interest in cognition of reality. During the social revolutions, the main institutions (guardians of traditions: monarchy, church, university) did not met the requirements that would satisfy the growing need for answers to practical questions in the field of machine production, economic policy, and mass education.

A new generation is emerging, which introduces a new concept "sociality of education." It includes the study of such relationships as "upbringing and education", "public good and individual service". One of the main goals of higher education is to teach future specialists how to solve problems in a specific subject area. Non-classical rationality required the abandonment of such categories as "absolute" and "unchanging". It is presented as a complex set of interactions between various practices, behaviors, and individual strategies.

The most interesting model of non-classical education is the model of the progressive education of the American philosopher (Dewey, 1920). He was not only a philosopher, but also a theorist and educator. His works "Schools of the Future", "Democracy and Education", "Experience and Education", "Progressive Education and Science of Education" have had a huge impact on the pedagogical thought of many countries. The author traveled a lot, giving lectures in China, Japan, Mexico, and Europe. In 1929 he visited the USSR and, upon returning home, published an article entitled "Impressions of Soviet Russia". Education, according to Dewey, is a continuation of adaptive abilities. 
The life is in development and novelty constantly appears in it, the educational process must also respond to this novelty, being in constant reorganization, reconstruction, and transformation. He put forward a completely new philosophy of educational technology; it is the idea of universal continuing education for all age categories. Newey differed from many thinkers, who in higher scientific education were focused only on such disciplines as mathematics, logic, and theoretical physics. Subsequently, after the atomic explosions in Hiroshima and Nagasaki, observing the confusion of the intelligentsia, their conflicting judgments about the morality of the chosen strategy, attributed this to the wrong concept of the state in relation to science. Science cannot be free from value and moral concepts (Dewey, 1920).

Any freely and independently thinking person carries in his soul a model of the universe, and his own concept of values. Humanist A. Schweitzer emphasized that for society, as well as for the individual, life without a worldview is a pathological violation of a higher sense of orientation (Schweizer, 1992). With sadness, Schweizer pointed out that in the modern world, instead of the truth, there has been a propaganda that freedom of thought is being abused. He supported the concept of I. Kant's "moral categorical imperative", where man was seen as the object of knowledge, not as a means.

The value of education is to help a person not only understand what business he is fit for, but also what he gives to society as a result of his activity. In Russia, starting in 1917, the ideological struggle for mass atheism dealt a fundamental blow to the traditions of prerevolutionary country and managed to form a new look for a student of the XX century. Faith in science has largely replaced faith in God. Philosophy, as a kind of knowledge, began to appear in two guises: as a science and as a theory of worldview.

So, one of the most important features of the nonclassical education paradigm was a detailed discussion of fundamental worldviews, theoretical, cognitive, philosophical and methodological problems.

The post-nonclassical (design) paradigm of the philosophy of education proceeds from the fact that in the modern world, more and more importance is attached to the productivity of scientific activity. As for classical and nonclassical science, it was one-sidedly connected with its own internal problems of constructing a theory, developing methods, or fundamental research. Today, post-non-classical science is an actor. With the construction of industry based on scientific knowledge, as well as state-supported project-oriented research, new forms of knowledge are emerging. Obtained by scientific means, experienced knowledge is transformed into controlled knowledge for decision making.

The breakdown of priorities and values has led to the fact that the very occupation of education and science has ceased to be regarded as a sphere of success in life, and therefore, the prestige of an academic career has been significantly reduced. XXI century develops new education technologies. The experience of managerial culture in the United Kingdom is very instructive, where the interaction of education and business has become an important factor in national politics. The meaning of the interaction between business and education is to take some mutual obligations: educational institutions through the introduction of external quality control mechanisms provide more effective training of personnel resources, and business, for its part, ensures the development of the material and technical and personnel base of the educational system, and also takes an active participation in the management of educational institutions.

At the end of the XX - the beginning of the XXI century there is a block of management disciplines actively involved in the educational field of many Russian universities. Leading science here is quality management, which has a certain theoretical and methodological status in the disciplinary organization of scientific and technical and socio-humanitarian knowledge, including problem-oriented and systemintegrated principles and approaches. All this creates new norms and norms of research and training, development of a complex of other disciplines of this unit, such as "Standardization and certification", "Statistical methods in quality management", "Information technologies in quality management and information protection" etc.

The most promising strategy for reconciling the interests of the state, education and business is the transition from purely market models of "mutual services" to closer and mutually beneficial partnerships and cooperation. These relations require a different culture in the education management: ensuring transparency and trust in the passage of financial information; readiness to organize and promote joint projects; ability to use the information provided by the 
collaborating system. Interdisciplinary and problem-oriented forms of research are being brought to the forefront of scientific research. Four factors play a big role: design, engineering, programming, and management. There are some fundamental discrepancies objectively inherent in the interaction between education and business:

- human factor (categorical forms of human subjectivity in business and education differ);

- differences in rhythms (processes in education are characterized by much greater predictability, stability and duration);

- differences in organization principles.

In Germany basic research is carried out mainly by higher educational institutions: institutes of the Max Planck Society. Their head office, located in Bonn, coordinates the activities of more than 50 research centers. Fraunhofer Society is oriented towards solving applied problems in Germany. The head office of this company, located in Munich, finances mainly areas of scientific research in which Germany has a competitive position. These new forms of knowledge are designated today as problemoriented research and disciplines, where the main thing is not just a statement of the problem from a methodological point of view or from the standpoint of scientific practice, but as a sociocultural understanding of science (Kryanev et al., 2012).

In the XXI century, the whole world entered the period of the fourth industrial revolution (Industry 4.0). Obviously, innovations of this period will affect not only the sphere of production, but also education. The impact of media, information, simulation technologies on human beings and problems of human-computer relations are at the heart of modern education.

In all countries of the world in the XXI century there are unprecedented conditions of higher education related to the occurrence of COVID19. Due to the introduction of quarantine, many educational institutions have switched to remote mode of operation. This required a new methodology for conducting the educational process. Considering the transformation of education in this period, Russian philosopher A.K. Grecko notes that innovative methods in the field of educational technologies include: personalized learning, artificial intelligence technology, machine learning and expert analysis. All this gives promising opportunities for the use of these technologies for students, teachers, heads of educational institutions and administrators of the education system (Grechko, 2015).

Leading universities of the world have begun to develop general theoretical bases and methodology of application of technologies of artificial intelligence in the educational process, because artificial intelligence education technologies can disrupt a teacher's dialogue with students, new approaches to teaching different disciplines are needed (Beck \& Lau, 2005).

\section{Methodology in education}

In education, functionality involves structuring the parts of the whole, complexity and system, their interconnection, and the whole (philosophy and education) to its structural parts (theoretical, methodological, etc.). Education has a structural and organizational embodiment, which includes specialized social and educational institutions at all levels. The unity of all the functions of philosophy and education implements their effectiveness, and the activity is the main characteristic of a specific way of human life, principles of its study (collective and individual) and their correlation with nature.

As for a systematic approach, a function represents, on the one hand, the activity of an object within the framework of a given system and its role; on the other hand, a type of connection between objects where changes in one cause alters in the other. This is a set of cognitive operations and actions for manifesting the essence of something. Functionality is a property of activity (purposefulness) and a type of it (productive orientation).

Methodology determines the activity functionality. In general, methodology is a system of concepts, methods, organization and construction of theoretical and practical activities. It is an area of activity where intellectual means (categories, concepts) are created and improved; it is focused on philosophy and education. At the same time, philosophical methodology is the doctrine of methods as a complex of processes leading to a certain result: choice of ways to direct research and training.

Here the emphasis is on the path to knowledge, focus on internal mechanisms, and logic of movement and organization of knowledge. Mechanism as a property of the system allows 
coordinating internal processes to maintain specific qualities (features) under external influences, which actualizes the methodological function of philosophy. It ensures the implementation of the activity approach, its connection with other approaches (thoughtactivity approach), helps to increase the role of philosophical functionality in the formulation and solution of certain problems.

Methodology should include the analysis of various ways of cognitive and practical human activity (scientific, aesthetic, religious, political, educational, etc.), as well as the description and analysis of various research approaches and concepts (elementary, systemic, typological, synergetic, etc.).

Thus, functionality and other approaches mentioned above are connected with theoretical and methodological substantiation of disciplinary and interdisciplinary structuring of science. This is due to the fact that the development of science is characterized by a complex interaction within disciplinary and interdisciplinary relations, emergence and transfer of paradigmatic attitudes. In the operational phase of classical science disciplinary research was dominated; in the nonclassical, predominant problem-disciplinary research was dominated; in the post-nonclassical, interdisciplinary approaches were priorities.

The ratio of subject (relevance of the subject scientific activities with a portion allocated to them of reality) and problem (identifying and limiting the unknown subject of research) leads to interdisciplinary synthesis. Disciplines (objectivity - problematic) become interdisciplinary (complexity and disciplinary integration through a common problem).

At the end of the XX century, the methodology began to be interpreted as a relatively independent type of activity (system thoughtactivity methodology). Therefore, the provision on the presence of a special socio-cultural property of methodology is legitimate. Everything is appeared in a special methodological thinking, where the functionality of criterion support and justification of reflexive activity is actualized. The organizational criteria of reflexivity are emphasized in the process of special methodological analysis. According to the founder of the methodological movement in Russia (Shchedrovitsky, 2003) "... methodological thinking is a universal form of thinking, covering all types of it, integrating into the sphere of thought-activity that develops its way, thinking activity, introducing them to the space implementation polypragmaty and polyprofessional one, organization and management, programming, organizational design, staying in the world of decision-making" (Shchedrovitsky, 2003). In 1964, G.P. Shchedrovitsky created the concept, which became one of the first in Russia in systematic research. In his work, he noted that methodology plays an important role in any field of activity. It provides the professional with the necessary tools: to summarize, to analyze, to identify errors and problems and to outline key areas in social change (Shchedrovitsky, 2003).

In our opinion, the ideas from the report of the famous Italian philosopher E. Agazzi at the XXIII World Philosophical Congress in Athens in 2013 are of particular interest here. The author outlined the main directions of work in the field of methodology showing the history of the philosophical study of the method. In this regard, he puts forward the concept of "methodological turn" as a characteristic feature of modern philosophy.

Deepening and expanding, intensifying the development "gives reason to talk about the "methodological turn" as a characteristic feature of modern philosophy. Today, many philosophers accept the expression "linguistic turn" as a suitable characteristic of modern philosophy. However, upon closer examination, this "turn" looks like a proposal for a new method of philosophizing, consisting in reducing the philosophical consideration of a problem to an analysis of the language in which this problem is formulated and discussed. This analysis may be armed with the latest, most powerful and subtle tools of semiotics and formal logic, applicable to any field of philosophical research: from philosophy of science to ontology, metaphysics, ethics, philosophy of law, etc.“ (Agazzi, 2014).

Agazzi notes the growth of attention to methodology in the XX century and realize that its development occurs due to the research of various methods of thinking: "it must be admitted that methodology has attracted more attention and development in one century than ever before, and this is of direct interest to philosophy. Indeed, if the distinguishing feature of philosophy is thinking (which is why we often call philosophers "thinkers"), and one of its original purposes is to distinguish between right and wrong "ways of thinking," it is immediately clear that we mean the internal articulation of thinking". Such articulation, however, does not coincide with the dichotomy of "right-wrong", 
because this ditochomy seems to be present inside each of the various "forms of thinking" that make up the real "articulation".

"For each of these forms we can try to determine what the right way of acting is, and we can call it the method inherent in this form or specific method of thinking. If we now consider the totality of all these particular methods of thinking and make them the subject of a special study, we will thereby define the field of methodology, which thus looks like the study of different methods of thinking. Of course, this enterprise cannot be recognized as having a primary interest for philosophy" (Agazzi, 2014).

At the same time, special attention is paid to the role of methodology in scientific knowledge, the connection of science and philosophy. "For this reason the rapid growth of methodology in the last century has been "fueled" by the introduction and development of new methods, both in philosophy and some special disciplines, on the basis of very fruitful feedback. For example, the philosophical notion of definition has been substantially enriched by the introduction of resource definitions and definitions through axioms in mathematics and mathematical logic. The latter one, in particular, had a direct impact on the semiotics and philosophy of language, giving a prototype of the concept of syntactic meaning and the doctrine of semantic holism" (Agazzi, 2014). Therefore, the results obtained in the framework of the application of individual thinking methods (phenomenological, semiotic, axiomatic, deductive, reductive, hermeneutic, transcendental, historical), is a set of truly philosophical knowledge.

Herewith Agazzi emphasizes that when analyzing the methods of thinking cannot be distracted from the content from the problems arising in different times and nowadays: "This occurs because of the motivation of philosophy that comes from the desire to rationally comprehend the world, ourselves, our social and physical environment, from the search of the meaning of our existence, and accordingly, the orientation of our lives. Philosophy in a broad sense is the search for wisdom and this method of attaining has never been abandoned in its history, and it certainly goes beyond pure methodology" (Agazzi, 2014).

The educational environment is constantly looking for new forms of learning requested by society during the development. The introduction and development of the multiplicity of new methods characterizing the heyday of methodology is a natural consequence of the complexity of the task of describing reality and knowledge. Moreover, various methods are complementary, but not opposing, and the discovery of new ones requires the solution of a lot of new problems (meaning and measurement of the probability of hypotheses), and old problems still awaiting solution (justifying induction).

Particularly Agazzi emphasizes the role of methodology in the study of rationality, intelligence in an interdisciplinary. So, it is closely related to scientific knowledge. Hegel pointed out this connection between scientific knowledge and method, method and content of thinking, their decisive role in philosophical searches: "The only thing I aspired to and am striving for in my philosophical research is scientific knowledge of the truth. Such cognition is the most difficult way, but only this way can be of interest and value to the spirit, if once it entering the path of thought, does not fall into vanity, but retains an irremovable will to truth. He soon finds that only this method is able to curb a thought, lead it to an object and keep it there. Subsequently, it is discovered that such a methodological way is a reproduction of the absolute content from which the thought at first was trying to leave and left; but this is reproduction in the deepest free element of the spirit" (Hegel, 1974).

In the system of methods the scientific method is very important. Here, the analysis of the methodology of science and education in their close connection with logic (including mathematical) from the work of American philosophers of science and logicians M. Cohen and E. Nagel is of considerable interest. The scientific method is emphasized by them: "It is aimed at discovering the facts, and its use should be guided by the facts discovered. However, as we have already noted, the nature of facts cannot be discovered without critical reflection. The knowledge of them cannot be equated with the direct data of our sensory perception".

Sensory experience poses the problem of knowledge; however, before it can be obtained, reflective analysis must be added to this direct and final experience" (Cohen \& Nagel, 2010).

Since each study comes from the sensation of the presence of a problem, therefore, no study can begin until some selection of the subject area has been carried out. In this regard, the authors pay 
attention to the fact that any research is special when it solves a specific problem and finding a solution is the end of it. Therefore, it is useless to collect facts if there is no problem to which they should relate.

The ability to formulate a problem, the solution of which will also be a solution of many others, is a rare "gift". The problems that everyone faces in everyday life can be solved, if it is possible to do it, by applying the scientific method. However, such problems, as a rule, do not raise large-scale issues.

The role of the logical form is emphasized here. Then the study is a judgment, for the truth of which there is sufficient reason. Therefore, the research, but not random techniques should determine what the facts are. Moreover, the facts depend on what level of research is being conducted. Therefore, there is no strict separation between facts and conjectures or hypotheses. During any research, the status of a judgment may vary from hypothesis to fact or from fact to hypothesis. Therefore, in the case of each socalled fact, one may wonder what grounds it has. At the same time, the full significance of the hypothesis is revealed in its implications, including through the scientific method (Pinkovetskaia et al., 2020).

The scientific method is always characterized by systematic doubt. No single judgment connected with facts is absolutely certain, and cannot have such good reasons that no other possible reasons can increase or decrease the degree of its credibility. Science requires and seeks logical reasons that are adequate in a logical sense for the judgments affirmed in it.

As a result, the science is always ready to drop theory when facts require doing it. The procedure, therefore, in the case of the appearance of theories incompatible with facts, provides a combination of willingness to make changes and the desire to adhere to existing theories. Verification of theories is approximate. It only shows that, within the framework of the experimental error, the experiment is compatible with the verified hypothesis. So, the authors believe that the method of science is more stable and important for scientists than any single result obtained with its help.

The scientific knowledge is subject to the mechanisms of self-organization and selfdevelopment, and it is a self-correcting process. "The science is a self-correcting process. It does not appeal to any special revelation or authority that provides undeniable and final information. It does not claim to be faultless, but relies on methods of development and testing of hypotheses to obtain informed conclusions. The principles of scientific research are discovered in the process of critical reflection and may also be subject to change in the process of study. The scientific method determines the establishment and correction of errors through the constant use them" (Cohen \& Nagel, 2010; Przybylski, 2019).

As an example, there is a reference to the application of the re-sampling method. Then the judgments studied by science are either confirmed in all possible experiments, or modified in accordance with new foundations. This self-correcting nature makes it possible to challenge any judgment, but at the same time it also gives confidence that theories accepted by science are more plausible than all alternative ones. Without pretending to be more reliable, which is facilitated by the existing foundations, the scientific method is successful in obtaining greater logical certainty than any other method ever invented (Prévot et al., 2018).

At the same time, in the process of collecting and weighing the grounds, there is a continuous appeal from facts to theories or principles and from principles to facts. Since there is nothing that by its nature would be certain, there are no absolutely first principles that would be selfevident or have to precede everything else.

Thus, M. Cohen and E. Nagel conclude that "in essence, the method of science is cyclical. We obtain the basis for principles by appealing to empirical material, which is considered a fact, and we select, analyze and interpret empirical material on the basis of principles. By virtue of this tactic of mutual concessions between facts and principles, everything that is doubtful is carefully examined either on the one hand or on the other hand" (Cohen \& Nagel, 2010).

So, the scientific method of studying education is closely connected with empirical material, theoretical analysis and intellectual quality.

Intensive changes in all spheres of life in modern society actualize the role of intelligence. It is necessary to solve non-standard tasks. According to many experts, in recent years, the transition to a "new economy" has begun. First of all, we are talking about the transition from the management of tangible assets and resources to the management of intangible assets and intellectual property. In countries that have recognized the need for such changes, an active search is 
underway for talented people with high qualities of intelligence. The era of "genius power", qualitatively new communication technology, first of all, technologies for joint creativity, systems with the active use of artificial intelligence, is coming. With full justification, it can be argued that the intellect and creative capabilities of man become resources for the development of society in the XXI century. The role of education is crucial here.

Experts are focusing on intelligence more and more. Such attention is determined by a lot of factors (Beck \& Lau, 2005). Neither raw materials, nor even technologies express the competitiveness of countries. First of all, it is determined by the quality of intelligence and thinking. The resource for the further development of society is in the mind and its quality, which indicates the objectivity of the transition to the noosphere, scientifically foreseen by the creator of the noospheric doctrine, such as V.I. Vernadsky (Vernadsky, 2013).

The idea of the role of the quality of thinking is one of the generic ideas of universal thought. The most ancient cultures have already expressed clearly the idea that the life way of a person, his consonance with the Logos of the Cosmos depends on the quality of thinking. This thought was of constructive importance for Russian culture. It was fully realized that the creative forces of an ethnos are determined by spiritual and mental qualities. For example, V.I. Vernadsky said the following: "The forces of a people are determined by their ability to work, honesty, moral and mental qualities, knowledge and talent" (Vernadsky, 2013).

In our opinion, under the modern conditions, a tendency has been identified for the disclosure of intellectual quality based on an analysis of the following components:

- identification of intelligence as a qualitative certainty of thinking;

- quality of intellectual activity;

- typology of intellectual quality.

The study must begin with the identification and analysis of the polysemy of "intelligence" (lat. Intellectus - mind, reason). In addition to philosophy, many sciences talk about intelligence: psychology in assessing the level of human intelligence; cybernetics and computer science in the study of artificial intelligence. And in the practical aspect of modern life, we often find discussions about "intelligence" or "intellectual activity".

In the philosophical understanding the intelligence is a qualitative definiteness of thinking, and we are faced with a key problem of its correlation with reason or rational activity. As it is known, since the epoch of I. Kant (Kant, 1993), in philosophical literature a qualitative difference is made between mind and reason. According to him, the reason is the formation of judgments, and the mind is the ability to form metaphysical ideas and to understand and comprehend (Tagunova et al., 2016).

Under the modern conditions, there are various approaches to the definition of the intelligence. On the one hand, it is a "part of thinking," expressed primarily through its creative component. On the other hand, following the development of the XX century, it is a "subject's ability to solve problems". From this point of view, it is a person's ability to find quality solutions to problems independently, effectively, i.e. with the least possible cost of mental resources. Also the intelligence is the ability of any organism to achieve some measurable degree of success when searching for one of many possible goals in a wide variety of environmental factors.

In high school, a long time ago there has been a discussion about how to form the intellectual abilities of future specialists. There are a lot of different points of view. We agree with the statement that not only individual qualities are expressed in the activity, but there is also the connection of the subject to the goals of the activity, other people, himself, his motives and values, character and ethical orientation. The task of higher education is to form the intellectual abilities, spiritual identification and motivation. The quality of intelligence is determined by how much the personality is able to get involved in the meanings of being and how much it realizes it in activities. Here it is appropriate to pay attention to the problems of studying the correlation of the psyche, brain and education. In particular, the modern Canadian philosopher D. Backhurst in his work "Minds, Brains, and Education" uses them (Bakhurst, 2013).

Now we are going to talk about noospheric significance of intelligence in general. Combined with its substantial spiritual and moral foundation, it has all the possibilities for accelerating the processes of transition to the noosphere, revealing the creative potential of 
universal human thought. All this actualizes the consideration of contextualization problems of methodology, including in the field of education.

In the XXI century there is the formation of a computer virtual environment, determined by the presence of man in the computer network and the presence of the computer network in the life world of human existence. According to scientific forecasts, in the XXI century, intensive multidisciplinary development of information technologies will continue. The practical activity of the educational process is of interest in the analysis of the promotion and use of information technology in education, which was published by UNESCO in Stephen Daggen's analytical memoir "Artificial Intelligence in Education: Measuring Learning Rate" in 2020. It notes that "effective use of artificial intelligence, data, analytics, as well as machine learning models, allow teachers to make the learning process more engaging through the use of immersion technologies in the virtual environment (Daggen, 2020).

In this work, it is noted that new technologies increase the importance of the role of the teacher, as they expand his capabilities, but cannot replace him. In the educational context, artificial intelligence is best viewed as an additional enhanced intelligence. Its application allows all parties to learn more information and draw conclusions needed to make more informed decisions.

As it was noted by the Swedish philosopher, futurologist, founder and director of the Institute for the Future of Humanity Nick Bostrom (1973), giving some characteristics of artificial intelligence, "Even today, some of the mandatory characteristics inherent in such an intelligent system can be recognized. It is clear that the ability to learn as an integral property of the system kernel should be invested in design, not added as a delayed consideration later in the form of an extension. The same applies to the ability to work effectively with uncertain and probable information. Most likely, the main modules of modern artificial intelligence should be the means of extracting useful information from the data from external and internal sensors and converting the received concepts into flexible combinatorial representations for further use in logical thinking processes (Bostrom, 2016).

The methodology of research of artificial intelligence consists in the development of a set of theories, methods and technologies. Its main directions are as follows:
- Development of machine learning techniques is a field of knowledge that explores algorithms that are trained on data in order to find regularities. It uses neural network methods, statistics, operations research, etc. to identify hidden useful information in the data. In this case, the instructions are not programmed to indicate where to look for data and how to draw conclusions. A number of basic techniques of machine learning have been proposed by the teacher of Moscow Institute of Physics and Technology, Doctor of Physical and Mathematical Sciences, S.A/ Shumsky, in the work "Machine Intelligence. Essays on the theory of machine learning and artificial intelligence" (Shumsky, 2020). Neuroscience is one of the methods of machine learning. This is a mathematical model, as well as its software or hardware embodiment, built on the principle of organization and functioning of biological neural networks: nerve cells of a living organism.

In-depth learning uses complex neural networks with multiple neurons and layers. Enhanced computing power and improved techniques are used to study these deep neural networks, as well as to detect complex patterns in huge data sets. Common applications include image recognition and speech recognition (Shumsky, 2020).

- Development of theoretical foundations of cognitive computing is the direction of artificial intelligence, the task of which is to ensure the process of natural interaction of man with a computer, similar to the interaction between people. The ultimate goal of artificial intelligence and cognitive computing is to simulate the human cognitive processes of the computer by interpreting images and speech with the appropriate response.

- Natural language processing is the ability of computers to analyze, understand and synthesize human language, including spoken language. We can now control computers using the usual language used in our daily learning process.

This will allow a faster transition to scientific research, since artificial intelligence makes it possible to memorize and process huge amounts of information. But the difficulty of this development is associated with the lack of the following resources: computer (capacity of operational and external memory) and human (science-intensive development of intelligent 
software requires the involvement of leading specialists from different fields of knowledge and organization of long-term research projects). This problem is raised in the work of $T$. Davenport "Implementation of artificial intelligence in business practice. Advantages and difficulties" (Davenport, 2021).

- Study of a new "high-tech culture" is an analysis of the change in cardinal values of the entire world civilization. In the work of Mark O'Connell "Artificial Intelligence and the Future of Mankind", the changes that will take place in the biological basis of a person with the help of information technologies were shown with specific examples. Internet and intelligent technologies will change the meaning of life and its attitude to the surrounding world, which show that digitalization of a person's entire life is a global anthropological challenge (O'Connell, 2021).

As we can see, artificial intelligence can mean scientific direction and various devices capable of reflection, simulating human intelligence. Speaking about changing educational programs, we should take into account the inclusion of artificial intelligence problems in various disciplines: technical and humanitarian ones.

\section{Discussion}

A systematic approach to the study of the phenomenon of education, its functions and its significance are reflected in different points of view on the educational process among scientists in different historical periods. Different approaches to the definition of the phenomenon of education can be summarized by the following conclusion. Education in any historical era is the bearer and condition of new processes in society, and in this regard it is always innovative.

In discussion papers, a vector is formed to continue the study of such aspects of education as identifying new components of scientific research, developing professional skills, expanding the cultural horizons of a future specialist and creating new value guidelines.

By the end of the 19th century, social pedagogy, the ideas of the labor school and reformist pedagogy constituted the traditional direction of the philosophy of education in Europe. So, in contrast to W. Humboldt, practical research and teaching, from the point of view of J. Newen, represent different functions. These functions should be divided between a scientific academy and university education. We see that later, homo sapience (rational man) and homo faber (practical man) will form the antithesis of education throughout European history.

We can agree with the German philosopher J. Habermas, who in his work "The Idea of the University" (1987) made a comparative assessment of the ideas of university education proposed by W. Humboldt and J. Newman and revealed the contradiction between these concepts, showing that the idea of classical education with the development of new needs of society will become obsolete (Habermas \& Blazek, 1987).

In the philosophy of education in Europe in the first half of the XX century there is a deep interest in the student as a phenomenon of social life, which is manifested in the philosophy of education Dewey. However, there was no uniformity in solving this problem. This can be seen from the surviving two main paradigms: pedagogical traditionalism and progressive concept of practical education.

Through a culturological approach to individual discourses, the authors highlight the problems of modernizing education in the cultural environment of Russia. In the religious and spiritual schools of Russia, the moral foundations of the system of emerging mass education were comprehended, original pedagogical concepts were developed, aimed at preserving the spiritual integrity of a person. All this led to the emergence in the subsequent period of a new concept for Russian pedagogy: the concept of "humanity".

The ideas of humanity are widely disclosed in the concept of A. Schweitzer, which emphasizes the role of a person to understand the meaning of culture in education, where the basis of culture is not material, but spiritual life. The crisis of the culture of the XX century, in his opinion, was due to the excessive pressure of collectives on an individual, who thereby was deprived of the opportunity to develop his spirituality and morality. He also supported Kant's idea of preserving the moral "categorical" imperative, where a person should be treated not as a means, but as an end.

Considering the modern works of philosophers such as G.P. Shchedrovitsky, E. Agazzi, M. Cohen and E. Nagel, we can draw conclusions about the identification of the features of 
scientific thinking and its creative process. Different types of thinking need to be considered in the education system. They distinguish between concrete and abstract, rational and figurative, verbal and visual, pragmatic and spiritual, etc. Thinking aimed at comprehending real objects is concrete. Thinking, comprehending the world of abstractions and idealizations and ideal constructions, functions as abstract. Scientific and philosophical thinking has such a character. Rational-pragmatic thinking asserts a utilitarian-practical orientation, and spiritual asserts an axiological orientation. Imaginative thinking has as its task a holistic "grasping" of things without their elemental detailing. Verbal and visual thinking are interrelated aspects of comprehending reality. Verbal thinking is realized in the word, while visual thinking operates with graphs and spatially structured schemes (visible forms of "manifested essence"). This type of thinking is widely used in teaching practice, helping to improve its quality. Broad prospects for visualization and interactivity of the educational process, for example, have modern tools focused on Internet technologies (animated images built on the basis of mathematical models of the studied object).

As it was noted by the Russian neurologist T.V. Chernigov, the development of cognitive research is not only of serious fundamental importance, but also of practical benefit for applied areas, primarily for medicine, pedagogy, psychology and education, for the development of new systems of artificial intelligence. She emphasizes the dependence of research on the education and training of cognitive scientists in the educational system. Her research is an example of the convergent and transdisciplinary development of science. The importance of this work is emphasized in her book, which presents an analysis of a series of studies by the author: "The Cheshire Smile of Schrödinger's Cat: Language and Consciousness". "The anthropological ideological role of this area of knowledge is indisputable: we want to understand who we are. It is also quite clear that such a complex environment requires not only a collaboration of scientists of different profiles, but specialists of a different, multidisciplinary type, and they need to be trained in the best universities" (Chernigovskaya, 2013).

The formation of digital reality is causing a change in the methodology of educational process, since artificial intelligence technologies can become personal assistants not only for teachers, but also for teachers. In the works of N. Bostrom, M. O'Connell, T. Davenport, S.
Duggen and S. A. Shumsky positive features that can be used in the learning process in distance learning are noted:

- ability to solve complex problems, store large amounts of information and work with them;

- ability to replenish existing knowledge, relative independence in assessing the situation and choosing situations and critical assessment of the incoming information material;

- ability to deductive conclusion, i.e. generating information that is not explicitly contained in the system. This quality allows an intelligent system to construct an information structure with new semantics and practical focus;

- $\quad$ ability to interact with a person who speaks another language.

On the other hand, there is a limitation for the full implementation of technologies in the educational environment:

- inertia of the educational system and potentially long process of mastering the methodology of artificial intelligence technologies by teachers.

- number of technological limitations that impede the development and implementation of the system. As the researchers emphasize, it is important to understand that an algorithm that can analyze training texts must learn from a high-quality database. For this, it is necessary not only to digitize sources, but also to create a system for checking meta information, context and content.

We can identify the problematic field of education, which today is at the intersection of several educational spaces (models):

- $\quad$ social space (dimension), where the problem of interaction between education and society is solved, i.e. civilizational tasks;

- cultural dimension (education and cultural values);

- $\quad$ anthropological dimension (formation of a person in education);

- ontological dimension (education as a world process).

Each dimension presupposes the identification of a specific goal of education, which in turn is expressed through a whole range of tasks and pedagogical methods. Only their combination can give a holistic picture of the goals and values 


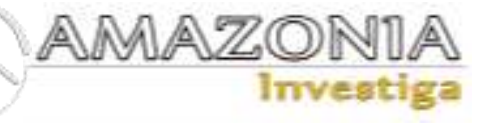

of education and find the missing links in it to support the sustainable development of society.

\section{Conclusions}

This topic is relevant, since informatization of society, democratization processes, tasks in the field of training and education of students are stimulating factors for continuous improvement of both the content of education and changes in its methodology. Summarizing the results of the study, the following conclusions are made:

- existence of the dynamics of the development of new educational concepts confirms that the phenomenon of education lies in its innovativeness;

- system analysis revealed trends in the methodology of the educational process in connection with the creation of new forms in educational, research and other intellectual activities, as well as in connection with the transition to new information technologies for education;

- $\quad$ summarizing the results of the discussion, it can be seen that the variability and integrative nature of education manifested itself in its orientation towards maintaining significant differences in the programs and functions of educational institutions in accordance with the diverse demands of the economic, social and cultural development of society;

- $\quad$ proposed strategy for the formation of a new digital educational paradigm based on the principles of consistency, diversification, integrity of the educational environment, individualization and cultural content.

\section{References}

Agazzi, E. (2014). Methodological turn in philosophy. Russian Studies in Philosophy, 9, 60-65.

Bakhurst, D. (2013). Mind, Brain, Education. Russian Studies in Philosophy, 11, 50-65. Available at: https://www.elibrary.ru/item.asp?id=20860044 Beck, U., \& Lau, C. (2005). Second Modernity as a Researcg Agenda: Theoretical and Empirical Explorations in ther "Meta-Change" of Modern Society. The British Journal of Socilogy, 56(4), 525-557.

Belkin, A. (2000). Another paradigm of education. Higher education in Russia, 1, 92-97. Available

https://cyberleninka.ru/article/n/esche-odnaparadigma-obrazovaniya
Bostrom, N. (2016). Artificial Intelligence: Stages. Threats. Strategies. Moscow: Expo. Chernigovskaya, T. V. (2013). Schrödinger's Cheshire Cat Smile: Language and Consciousness. Moscow: Publishing House Languages of Slavic Culture.

Cohen, M., \& Nagel, E. (2010). Introduction to Logic and the Scientific Method. Chelyabinsk: Socium.

Daggen, S. (2020). Artificial intelligence in education: changing the pace of learning. Moscow: UNESCO Institute for Information Technologies in Education. Available at: https://iite.unesco.org/wpcontent/uploads/2020/12/Steven_Duggan_AIin-Education_2020_RUS.pdf

Davenport, T. (2021). Implementation of artificial intelligence in business practice. Benefits and Difficulties. Moscow: Alpina.

Dewey, J. (1920). Reconstruction of Philosophy. New York: H. Holt and Company.

Grechko, P. K. (2015). Onto-methodological discourse of the present: Historical advancement and its challenges. Moscow: LENAND.

Habermas, J., \& Blazek, J. R. (1987). The idea of the university: Learning processes. New German Critique, 41, 3-22.

Hegel, G. W. F. (1974). Encyclopedia of Philosophy. Volume 1: Science of Logic. Moscow: Thought.

Humboldt, W. (1985). Language and philosophy of culture. Moscow: Progress. Available at: https://www.phantastike.com/philosophy/yazyk _i_filosofiya_kultury/pdf/

Kant, I. (1993). Criticism of Pure Reason. St. Petersburg: Time-out.

Kireevsky, I. V. (2014). Complete works in two volumes. Moscow: Directmedia.

Kryanev, Yu. V., Motorina, L. E., \& Pavlova, T. P. (2012). Philosophy of information and communication systems. Monograph. Moscow: Moscow Aviation Institute Publishing House.

Locke, W. J. (2001). Favorites. Moscow: Publishing House of Shalva Amonashvili.

Milyukov, P. N. (2013). Essays on the history of Russian culture. Moscow: Ripol Classic.

Newman, J. H. (1996). The Idea of a University. New Haven: Yale University Press.

O'Connell, M. (2021). Artificial intelligence and the future of humanity. Moscow: Litres.

Pinkovetskaia, I., Lyubovtseva, E., Arbeláez-Campillo, D., \& Rojas-Bahamón, M. (2020). Small and medium enterprises in Russia and other countries. Amazonia Investiga, 9(25), 99-106.

https://amazoniainvestiga.info/index.php/amazo nia/article/view/1034 
Prévot, A. C., Clayton, S., \& Mathevet, R. (2018). The relationship of childhood upbringing and university degree program to environmental identity: Experience in nature matters. Environmental Education Research, 24(2), 263-279.

Przybylski, P. (2019). A New Model of Education and Upbringing in Polish School. 21st Century Pedagogy, 3(1), 35-41.

Schweizer, A. (1992). Reverence for life. Moscow: Progress.

Shchedrovitsky, G. P. (2003). Guide to Organization, Leadership and Management Methodology. Moscow: Business.

Shumsky, S. A. (2020). Machine intelligence. Essays on the theory of machine learning and artificial intelligence. Moscow: Infra-M.
Tagunova, I. A., Selivanova, N. L., \& Valeeva, R. A. (2016). The Category of Upbringing in Russian and Western Studies. International Electronic Journal of Mathematics Education, 11(1), 3-11.

Tsvyk, I. V. (2011). The problem of the relationship of faith and reason in Russian spiritual and academic philosophy of the XIX century. RUDN University Bulletin. Philosophy Series, 4, 41-51.

Vernadsky, V. I. (2013). The tasks of higher education of our time. Moscow University Bulletin. Series 20. Teacher Education, 4, 107-113. Available https://cyberleninka.ru/article/n/zadachivysshego-obrazovaniya-nashego-vremeni 